\title{
cDNA Cloning of Heat-inducible HSP70, a 70.6 kDa Heat Shock Protein, in Japanese Flounder Paralichtys olivaceus
}

\author{
Yoshihiro Yokoyama, ${ }^{* 1, \dagger}$ Hisashi Hashimoto, ${ }^{* 2}$ Satoshi Kubota, ${ }^{* 2}$ \\ Masato Kinoshita, ${ }^{* 2}$ Haruhiko Toyohara, ${ }^{* 2, \dagger}$ Morihiko Sakaguchi, ${ }^{* 2}$ \\ Masaru Tanaka, ${ }^{* 2}$ Tadahisa Seikai, ${ }^{* 3}$ and Masao Kanamori ${ }^{* 1}$ \\ ${ }^{*}$ Interdisciplinary Research Institute for Biosciences, Mukogawa Women's University, \\ Ikebiraki, Nishinomiya, Hyogo 663-8558, Japan \\ ${ }^{*}$ Division of Applied Biosciences, Graduate School of Agriculture, Kyoto University, \\ Sakyo, Kyoto 606-8502, Japan \\ ${ }^{*}$ Fisheries Research Station, Graduate School of Agriculture, Kyoto University, \\ Maizuru, Kyoto 625-0086, Japan
}

(Received March 16, 1998)

\begin{abstract}
Full-length cDNA for a $70.6 \mathrm{kDa}$ heat-inducible heat shock protein (HSP70), a member of the HSP70 family, was isolated from a cDNA library of cultured cells in early passage originated in Japanese flounder embryos (JFE cells). It has a single ORF of 1920 bp that encodes a protein of 70.6 $\mathrm{kDa}$. Japanese flounder HSP70 contains an EEVD peptide motif at C-terminal end which is a common feature of the cytosolic HSP70 family. Japanese flounder HSP70 is $86.0 \%, 83.8 \%$, and $83.6 \%$ identical in primary structure to chinook salmon HSP70, bovine HSP70, and human HSP70, respectively. Japanese flounder HSP70 is also $83.6 \%$ identical to Japanese flounder HSC71. These results suggest that the amino acid sequence of the cytosolic HSP70 family, HSP70 and HSC71, has been highly conserved among vertebrates. Northern blot analysis showed that HSP70 mRNA was induced with heat shock treatment in the JFE cells in early passage.
\end{abstract}

Key words: HSP70, heat shock protein, heat-inducible, cDNA, Japanese flounder

\section{Introduction}

All organisms synthesize a few evolutionary-conserved proteins called heat shock proteins or HSP, recently called a stress protein, in response to various harmful environmental stresses. ${ }^{1-3)}$ The most abundant and conserved HSP has a molecular mass of about $70 \mathrm{kDa}$. In eukaryotes, HSP70 are encoded by heat-inducible HSP70 genes and usually their basal expression is negligible. HSP70 is known to act as a molecular chaperon in cells under stress conditions. In fact, in vitro studies revealed that the cultured fish cells synthesized HSP70 under adverse conditions such as heat shock, heavy metal ions, and sodium arsenite. ${ }^{1)}$

The Japanese flounder is one of the most commercially valuable fish and so becomes an important experimental marine fish in Japan. The culture of Japanese flounder has been successful. During the transportation and breeding in the farm, the embryos could be exposed to adverse environmental changes. In the previous report, we cloned the cDNA of HSP70 homolog, a $71 \mathrm{kDa}$ heat shock cognate protein (HSC71), from Japanese flounder embryo and found that the flounder HSC71 mRNA was constitutively expressed under normal and also stress conditions in the cultured cells in early passage originated in Japanese flounder embryos ${ }^{4)}$ in contrast to stress-inducible HSP70 reported on other vertebrates such as human, ${ }^{5)}$ bovine, ${ }^{6)}$ or rat. ${ }^{7)}$ In addition, HSC71 functions as a molecular chaperon. ${ }^{1-3)}$ These findings suggested that the Japanese flounder HSC71 is indispensable for development under normal and also stress conditions. However, in Japanese flounder, little is known about stress-inducible proteins which may have important roles for the accommodation to transitory adverse changes of environment and also for development under stress conditions. Those gene structures in Japanese flounder are also unknown. As a preliminary to resolve the role of stress inducible proteins in the flounder embryos under stress conditions, we decided to clone the stress-inducible HSP70 cDNA, referred to here as Japanese flounder HSP70 cDNA. Nucleotide sequence and expression analyses revealed that the isolated clone represents a heat-inducible HSP70 cDNA.

\section{Materials and Methods}

Japanese Flounder Embryos and Culture of cells Japanese flounder Paralichtys olivaceus eggs (embryos

\footnotetext{
† To whom correspondence should be addressed. E-mail: yokoyama@mwu.mukogawa-u.ac.jp or toyohara@kais.kyoto-u.ac.jp

The following abbreviations are used: HSC, heat shock cognate protein(s); HSP, heat shock protein(s); RT-PCR, reverse transcription-polymerase chain reaction; bp, base pair; kb, kilobase; dNTP, deoxynucleotide triphosphate; JFE cells, cells originated in Japanese flounder embryo; SDS, sodium dodecyl sulphate; SSC, standard sodium chloride/sodium citrate buffer. The DDBJ, GenBank and EMBL accession number for Japanese flounder HSP70 is AB010871.
} 
in eyed period) were provided by Yamagataya Suisan (Nantan, Hyogo, Japan). About $1 \times 10^{4}$ eggs were gently stirred in sea water containing antibiotics (200 units $/ \mathrm{m} l$ penicillin, $200 \mu \mathrm{g} / \mathrm{m} /$ streptomycin, and $250 \mu \mathrm{g} / \mathrm{m} l$ kanamycin), washed in $\mathrm{Ca}^{2+}$ and $\mathrm{Mg}^{2+}$-free phosphate-buffered saline (PBS-)containing antibiotics, and mashed in $2 \mathrm{~m} l$ of PBScontaining $0.25 \%$ trypsin and antibiotics. The suspension was filtered through a stainless-steel mesh. The resulting suspension of cells and small tissue pieces was combined with $10 \mathrm{~m} l$ Leibovitz's L15 medium supplemented with 25 mM 4-(2-hydroxyethyl)-1-piperazine-ethanesulfonic acid, penicillin $(100$ units $/ \mathrm{m} l)$, streptomycin $(50 \mu \mathrm{g} / \mathrm{m} l)$, and $15 \%$ fetal bovine serum (FBS, Biological Industries), and seeded into $25 \mathrm{~cm}^{2}$ plastic flasks (Corning). The cells, originated in Japanese flounder embryo (JFE cells), were cultured at $20^{\circ} \mathrm{C}$ in air using the Leibovitz's L15 medium. The primary cultures were maintained for 7-10 days, then subcultured by trypsinization with $0.25 \%$ trypsin in PBSat a split ratio of $1: 2$ several times until experimental use. A half volume of the medium was renewed every 3-4 days.

\section{Preparation of $R N A$}

Total RNA from JFE cells in early passage was isolated by ultracentrifugation in $5.7 \mathrm{M}$ cesium chloride after homogenization in $4 \mathrm{M}$ guanidinium thiocyanate. ${ }^{8)}$ Poly $(A)^{+}$RNA was enriched by chromatography on oligo (dT) cellulose (Collaborative Biomedical Products) or on Oligotex-dT30 (Takara).

\section{RT-PCR Cloning}

To obtain a partial sequence of Japanese flounder HSP70 gene, PCR was conducted with degenerate oligonucleotide primers having the following sequences: 5'-ATCGAYCTSGGSACYACCTACTC-3' as the sense primer and 5'-GCACCGTASSCSACCGCYTCRTC-3' as the antisense primer, where $R=A+G, S=G+C$, $\mathrm{Y}=\mathrm{C}+\mathrm{T}$. These correspond to the amino acid sequences, IDLGTTYS and DEAVAYGA, respectively, which are identical in the vertebrate HSP70 family such as chinook salmon HSP70, ${ }^{* 4}$ human HSP70, ${ }^{5)}$ Japanese flounder $\mathrm{HSC7}^{4)}$ (shown in Fig. 2), bovine HSP70) and rat $\mathrm{HSP} 0^{7}$ or $\mathrm{HSC} 71{ }^{10}$ Single stranded CDNA was synthesized from $1 \mu \mathrm{g}$ of total RNA of the JFE cells with 200 units of MMLV-RT (Gibco-BRL) in a $20 \mu l$ reaction mixture comprising $50 \mathrm{~mm} \mathrm{KCl}, 20 \mathrm{~mm}$ Tris- $\mathrm{HCl}(\mathrm{pH} 8.4)$, $2.5 \mathrm{mM} \mathrm{MgCl}_{2}, 0.1 \mathrm{mg} / \mathrm{m} l \mathrm{BSA}, 1 \mathrm{mM}$ each dNTP, $5 \mu \mathrm{M}$ random hexamer, and 20 units of ribonuclease inhibitor RNasin (Toyobo). A quarter of the resultant cDNA was used as a template for the PCR, which was carried out in a $25 \mu l$ solution comprising eight units of Tth DNA polymerase (Toyobo), $50 \mathrm{~mm} \mathrm{KCl,} 20 \mathrm{mM}$ Tris- $\mathrm{HCl}(\mathrm{pH} 8.4)$, $2.5 \mathrm{mM} \mathrm{MgCl} 2,0.1 \mathrm{mg} / \mathrm{m} l \mathrm{BSA}, 0.2 \mathrm{mM}$ each dNTP, and $0.2 \mu \mathrm{M}$ each primer. The PCR conditions were $30 \mathrm{~s}$ at $95^{\circ} \mathrm{C}, 30 \mathrm{~s}$ at $56^{\circ} \mathrm{C}$, and one min at $72^{\circ} \mathrm{C}$ for 25 cycles (Astec, Program Temp Control System PC-700). The resultant products of the expected size, approximately $1100 \mathrm{bp}$, were subcloned in pBluescript $\mathrm{II} \mathrm{KS}^{+}$(Stratagene). DNA sequencing analysis revealed that there was a cDNA fragment of HSP70-like gene in the pool of the
PCR products.

\section{cDNA Cloning and Sequencing}

The synthesis of double-stranded cDNA was accomplished with a ZAP cDNA Synthesis Kit (Stratagene) using poly (A) ${ }^{+}$RNA prepared from JFE cells heat-shocked at $37^{\circ} \mathrm{C}$ for $20 \mathrm{~min}$ by chromatography on oligo (dT) cellulose. The cDNAs were size-fractionated on a CHROMA SPIN-100 column (Clontech) and then adapter-ligated prior to the generation of an oligo (dT) primed library in Uni-ZAP/EcoRI/Xhol/CIAP (Stratagene). The cDNA library was screened with a cDNA fragment obtained on PCR as a probe. Plaque hybridization was performed at $42^{\circ} \mathrm{C}$ in a solution comprising $5 \times \mathrm{SSC}(1 \times \mathrm{SSC}=150 \mathrm{~mm}$ $\mathrm{NaCl}, 15 \mathrm{~mm}$ sodium citrate, pH 7.0$), 0.1 \% \mathrm{SDS}, 50 \%$ formamide, $100 \mathrm{mg} / \mathrm{m} l$ denatured salmon sperm DNA, $0.6 \%$ Ficoll $400,0.6 \%$ polyvinylpyrrolidone $100,0.6 \%$ BSA, and ${ }^{32} \mathrm{P}$ labeled probe prepared with a Megaprime DNA labelling system (Amersham International PLC). After hybridization, the filters were washed four times with $2 \times \mathrm{SSC}$ at room temperature and three times with $2 \times \mathrm{SSC}, 0.5 \%$ SDS at $68^{\circ} \mathrm{C}$ prior to autoradiography. Plasmids ( $\mathrm{pBluescript} \mathrm{SK}^{-}$) containing the cDNA insert were obtained by in vivo excision from positive single plaques according to the manufacturer's instruction (Stratagene). After subcloning into pBluescript II $\mathrm{KS}^{+}$, DNA fragments were sequenced by a PCR procedure employing fluorescent dideoxynucletides and a model 373A automated sequencer (Applied Biosystems Inc.). The sequences reported in this paper were determined on both strands.

\section{Northern Blot Analysis}

The JFE cells in early passage were heat-shocked at $37^{\circ} \mathrm{C}$ for 0,20 or $40 \mathrm{~min}$. Immediately after the treatment, the cells were collected. Northern blot analysis was carried out using total RNA (10 $\mu \mathrm{g})$ prepared from the cells. The cloned cDNA fragment of Japanese flounder HSP70 (1898 to $2112 \mathrm{bp}$ ) containing $3^{\prime}$-untranslated regions (1921 to $2112 \mathrm{bp}$ ) was used as the probe for hybridization. As an internal control, the cDNA fragment of Japanese flounder HSC71 containing $3^{\prime}$-untranslated regions ${ }^{4}$ was used as the probe for hybridization. Hybridization was performed under the same condition described above.

\section{Results and Discussion}

\section{Cloning and Sequence of the Full-length cDNA for HSP70}

An RT-PCR strategy for cloning a partial cDNA of Japanese flounder HSP70 successfully yielded a cDNA fragment of approximately $1100 \mathrm{bp}$. DNA sequencing analysis revealed that the fragment was homologous to heat inducible mammalian HSP70 gene ${ }^{5-7)}$ (data not shown). In order to obtain a full length cDNA of flounder HSP70, a cDNA library of heat-shocked JFE cells in early passage was screened with the PCR-derived cDNA fragments as a probe. By screening of $10^{5}$ independent recombinant phages, hundreds of positive clones were isolated. DNA sequencing analyses on both $5^{\prime}$ and $3^{\prime}$-end of ten clones

\footnotetext{
${ }^{*_{4}}$ M. T. Hargins, D. D. Dauble, S. Howard, P. Candido, E. Hickey, and L. A. Werber: The DDBJ, GenBank and EMBL accession number for chinook salmon HSP70 is Q91233 (unpublished).
} 


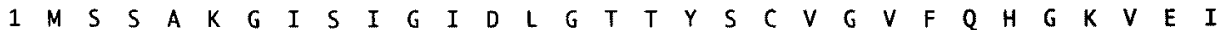

1 ATGTCTTCAGCGAAGGGAATATCCATTGGCATTGATTTGGGACCACCTATTCTTGTGTTGGGGTITCCAACATGGCAAAGTGGAGATC $\begin{array}{lllllllllllllllllllllllllllllll}31 & I & A & N & D & Q & G & N & R & T & T & P & S & Y & V & A & F & T & D & T & E & R & L & I & G & D & A & A & K & N & Q\end{array}$ 91 ATTGCCAACGACCAGGGCAACAGGACAACTCCCAGCTATGTGGCCTTTACCGACACAGAGAGGCTCATTGGAGATGCTGCCAAGAACCAG

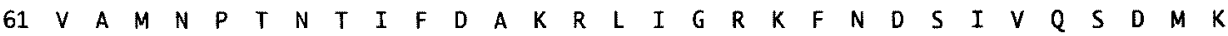
181 GTTGCCATGAACCCCACCAATACAATATTTGACGCCAAGCGACTAATAGGAAGAAAGTTTAATGACTCCATCGTCCAGTCCGACATGAAA

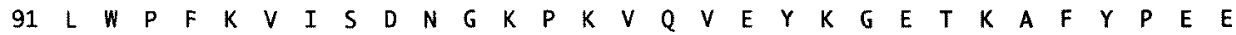
271 CTTGGCCTTTCAAGGTGATCAGTGATAACGGAAAGCCCAAAGTTCAGGTGGAGTATAAAGGCGAAACCAAGGCCTTCTACCCTGAAGAA $\begin{array}{lllllllllllllllllllllllllllllll}121 & I & S & S & M & V & L & V & K & M & K & E & I & A & E & A & Y & L & G & Q & K & V & S & N & A & V & I & T & V & P & A\end{array}$ 361 ATCTCGTCAATGGTCCTGGTTAAAATGAAGGAGATAGCTGAGGCCTACCTGGGACAAAAGGTTTCAAATGCAGTCATCACAGTGCCAGCT $\begin{array}{llllllllllllllllllllllllllllllll}151 & Y & F & N & D & S & Q & R & Q & A & T & K & D & A & G & V & I & S & G & L & N & I & L & R & I & I & N & E & P & T & A\end{array}$ 451 TATTTCAATGATTCTCAGAGGCAAGCCACTAAGGATGCTGGAGTGATCTCTGGTCTGAATATTCTGAGGATCATCAACGAACCCACAGCA

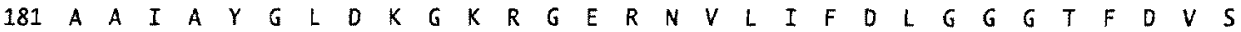
541 GCAGCGATTGCCTACGGCTTAGATAAAGGTAAAAGAGGAGAGCGCAACGTGCTCATCTITGATCTCGGTGGAGGCACCTTTGACGTGTCC

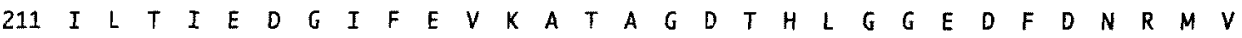
631 ATCCTGACCATTGAGGACGGCATCTTTGAGGTAAAAGCCACTGCAGGAGACACACACCTTGGTGGGGAGGACTTTGACAATCGGATGGTC

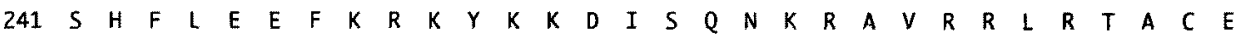
721 AGTCACTTCCTCGAGGAATTTAAAAGAAAGTACAAGAAAGACATCAGCCAAAATAAGAGAGCAGTTAGGAGACTGCGCACAGCTTGTGAG

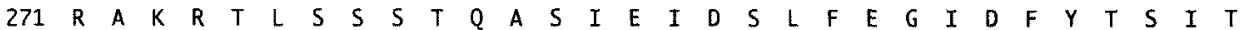
811 AGAGCGAAGAGGACCCTGTCCTCAAGCACCCAGGCCAGCATTGAAATCGACTCTCTGTTTGAGGGCATCGACTTCTACACCTCCATCACA

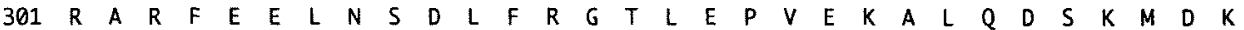
901 AGGGCACGCTITGAGGAGCTCAACTCAGATCTCTTCAGGGGAACACTGGAGCCAGTGGAGAAAGCCCTACAAGATTCCAAGATGGATAAG $\begin{array}{lllllllllllllllllllllllllllllll}331 & S & K & I & H & E & I & V & L & V & G & G & S & T & R & I & P & K & I & Q & K & F & L & Q & D & F & F & N & G & R & E\end{array}$ 991 TCCAAGATCCATGAAATCGTCCTGGTTGGTGGCTCCACAAGAATTCCCAAAATCCAGAAGTTCTTGCAAGATTTCTTTAATGGCAGAGAA

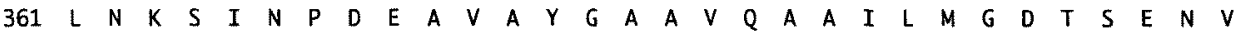
1081 CTGAACAAGAGTATCAACCCAGATGAAGCTGTGGCTTATGGTGCAGCAGTCCAGGCTGCTATCCTCATGGGTGACACTTCGGAGAACGTC

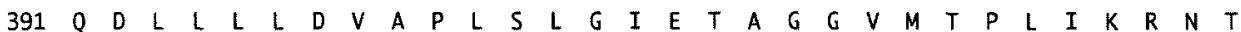
1171 CAAGATCTGCTGCTGCTGGACGTGGCTCCCCTGTCTCTGGGTATTGAGACTGCTGGTGGAGTCATGACACCTCTGATCAAACGCAACACA

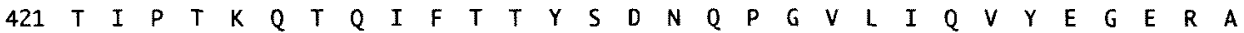
1261 ACTATCCCCACCAAGCAAACCCAGATCTTCACCACCTACTCAGATAACCAGCCTGGTGTGCTAATTCAGGTGTATGAGGGCGAGAGAGCC

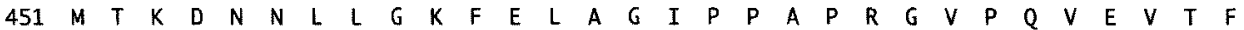
1351 ATGACCAAGGACAACAACCTCCTGGGCAAGTTTGAGCTCGCTGGCATCCCTCCTGCTCCCCGAGGCGTACCGCAGGTGGAGGTAACTITC $\begin{array}{lllllllllllllllllllllllllllllll}481 & D & I & D & A & N & G & I & L & N & V & S & A & V & D & K & S & T & G & K & E & N & K & I & T & I & T & N & D & K & G\end{array}$ 1441 GACATTGATGCCAACGGAATTCTGAACGTGTCTGCTGTCGACAAAAGCACCGGCAAAGAAAACAAAATCACCATCACAAATGACAAGGGC

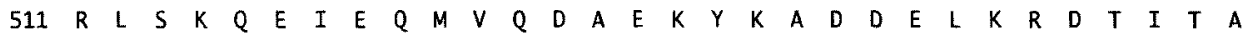
1531 CGCCTCAGCAAACAGGAGATTGAGCAGATGGTACAGGATGCTGAGAAGTACAAGGCTGATGACGAGCTGAAGAGGGACACGATTACAGCA

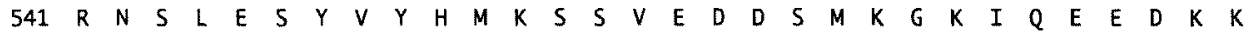
1621 AGGAACTCACTGGAGAGTTACGTTTACCACATGAAGAGCAGCGTTGAGGATGACAGTATGAAAGGAAAGATTCAGGAGGAGGACAAAAAA

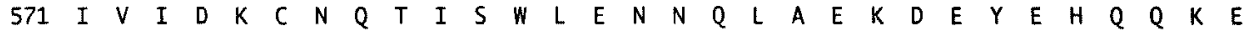
1711 ATTGTCATTGACAAGTGCAACCAGACAATCTCCTGGCTGGAGAACAACCAGCTGGCAGAGAAGGACGAGTATGAGCACCAGCAGAAGGAA 601 L E K V V C N N P 1801 CTAGAGAAGGTGTGCAATCCGATTGTGACAAAGCTGTACCAGGGAGCGGCACCACCACCAGGAGGCAGCAGCGGCCATGCAGGAGGCAAC

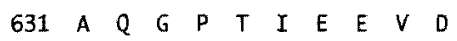
1891 GCTCAGGGTCCCACTATTGAGGAGGTGGACIAATAACATGAAAGTCATGTCAATATTICACATGGCTATGATGTTGGACATTAAATTGA 1981 GTITTCTTCCTCGTCTGCATCCACTTTIACTCATTATAATTTATTTCTGCTITGTTCACTTTCCTTGTGTCCACTCACATTGTATTTT 2071 AAATAAAGTITTATGAAAACAAAAAAAAAAAAAAAAAAAAAA

Fig. 1. Nucleotide and deduced amino acid sequences of the HSP70 cDNA of Japanese flounder. The position of initiation (base pairs 1 to 3 ), termination (1921 to 1923) codons, and a putative polyadenylation signal (2072 to 2077) in the sequence is underlined.

selected at random revealed that they encoded the same gene (data not shown). As a result, we determined the nucleotide sequences of the longest clone.

The cDNA of Japanese flounder HSP70 consists of 2198 nucleotides with poly (A) tail (Fig. 1). The in-frame stop codon in the $5^{\prime}$ and $3^{\prime}$ regions of the cDNA indicated that the clone contains the entire coding regions. The coding region includes 1920 nucleotides and corresponds $640 \mathrm{ami}$ no acids with a predicted mass of $70.6 \mathrm{kDa}$.

Figure 2 shows the comparison of the nucleotides sequence of HSP70 from Japanese flounder with those of other vertebrates. Japanese flounder HSP70 contains a EEVD (Glu-Glu-Val-Asp) peptide motif at $\mathrm{C}$-terminal end which is the common feature of the cytosolic HSP70 family. ${ }^{1)}$ Comparison with protein sequences in the SWISS-PROT database by FASTA indicated that Japanese flounder HSP70 is $86.0 \%, 83.8 \%, 83.6 \%$, and $82.8 \%$ identical in primary structure to chinook salmon HSP70, bovine HSP70, ${ }^{6}$ human HSP70, ${ }^{5)}$ and rat HSP,") respectively. Obviously the HSP70 amino acid sequence has been highly conserved among various vertebrate taxa. On the other hand, similarity to the HSC71s, which are heat-noninducible HSP70 homologs and expressed constitutively, are also high. Similarity to Japanese flounder HSC71 (Fig. 2), ${ }^{4}$ human HSC71, ${ }^{11}$ bovine HSC71, ${ }^{9}$ and rat $\mathrm{HSC}^{100}$ amount to $83.6 \%, 83.6 \%, 82.9$, and $83.7 \%$, respectively. These results suggest that the amino acid sequence of the cytosolic HSP70 family, HSP70 and 


\begin{tabular}{|c|c|}
\hline $\begin{array}{r}\text { jfHSP70 } \\
\text { sHSP70 } \\
\text { hHSP70 } \\
\text { jfHSC71 }\end{array}$ & 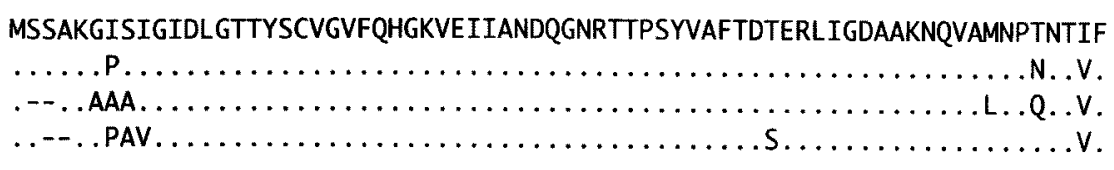 \\
\hline $\begin{array}{l}\text { jFHSP70 } \\
\text { SHSP70 } \\
\text { hHSP7O } \\
\text { jFHSC71 }\end{array}$ & 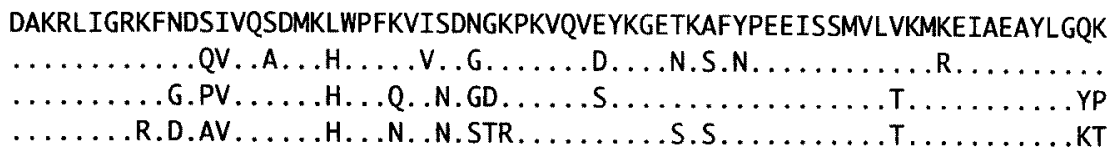 \\
\hline $\begin{array}{l}\text { jfHSP70 } \\
\text { SHSP70 } \\
\text { hHSP70 } \\
\text { jfHSC71 }\end{array}$ & 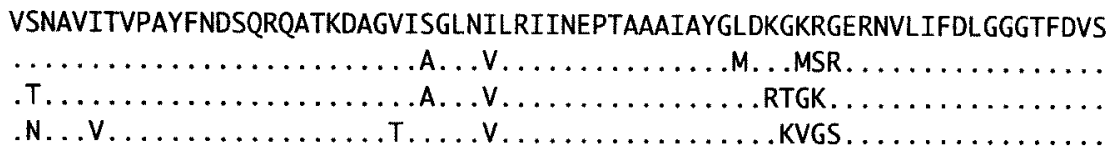 \\
\hline $\begin{array}{r}\text { jfHSP70 } \\
\text { sHSP70 } \\
\text { hHSP70 } \\
\text { jfHSC71 }\end{array}$ & 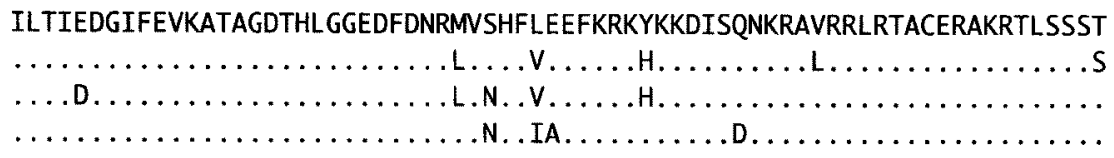 \\
\hline $\begin{array}{r}\text { jfHSP70 } \\
\text { SHSP70 } \\
\text { hHSP70 } \\
\text { jfHSC71 }\end{array}$ & 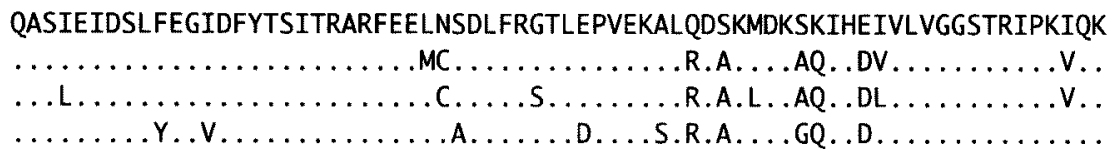 \\
\hline $\begin{array}{r}\text { jfHSP70 } \\
\text { SHSP70 } \\
\text { hHSP70 } \\
\text { jfHSC71 }\end{array}$ & 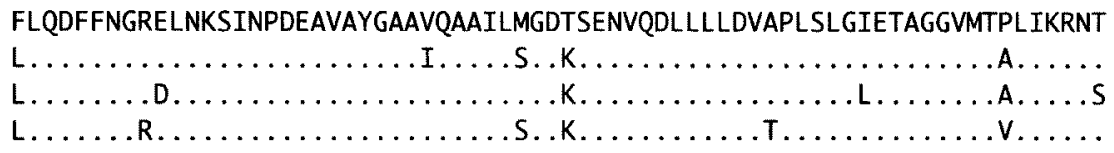 \\
\hline $\begin{array}{r}\text { jfHSP70 } \\
\text { SHSP70 } \\
\text { hHSP70 } \\
\text { jfHSC71 }\end{array}$ & 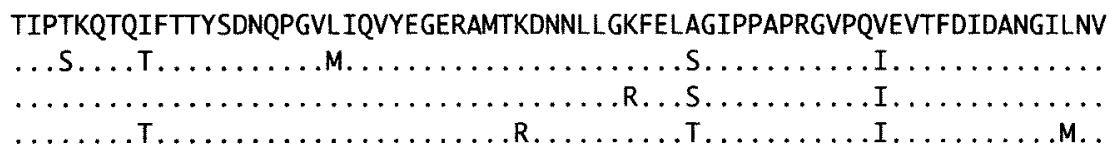 \\
\hline $\begin{array}{r}\text { jfHSP70 } \\
\text { sHSP70 } \\
\text { hHSP70 } \\
\text { jfHSC71 }\end{array}$ & 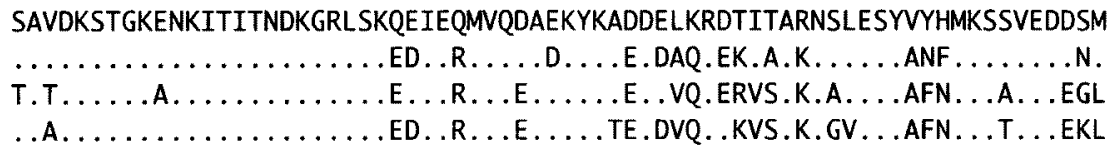 \\
\hline $\begin{array}{r}\text { jfHSP70 } \\
\text { SHSP70 } \\
\text { hHSP70 } \\
\text { jfHSC71 }\end{array}$ & 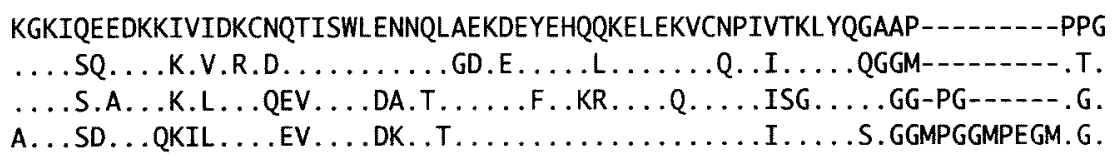 \\
\hline $\begin{array}{r}\text { jFHSP70 } \\
\text { SHSP70 } \\
\text { hHSP70 } \\
\text { jfHSC71 }\end{array}$ & $\begin{array}{l}\text { GS---SGHAGGNAQGPTIEEVD } \\
\text { CCGDQARTSS.DSS........ } \\
\text { FGAQG---PK..SGS } \\
\text { FGGAGGAAPGA.S-S...... }\end{array}$ \\
\hline
\end{tabular}

Fig. 2. Protein comparison. Deduced amino acid sequence of a protein encoded by the cloned Japanese flounder cDNA (jfHSP70) is compared to that of chinook salmon HSP70 (sHSP70), human heat-inducible HSP70 (hHSP70), ${ }^{5)}$ and Japanese flounder HSC71 expressed constitutively $($ jfHSC71).4) Only different amino acids are indicated and hyphens mark deletions.

HSC71, has been highly conserved among vertebrates.

\section{Heat-inducible Expression of Japanese Flounder HSP70 $m R N A$ \\ To investigate the expression pattern of Japanese flound- er HSP70 mRNA, Northern blot analyses of total RNA from normal or heat-shocked cells were conducted (Fig. 3). The probe for hybridization was prepared from the cloned HSP70 cDNA fragments (1898 to $2112 \mathrm{bp}$ ) that consisted of mainly $3^{\prime}$ untranslated regions (1921 to $2112 \mathrm{bp}$, Fig. 1) to tighten the specific affinity on HSP70 mRNA rather than HSC71 mRNA. In those regions, the similarity of Japanese flounder HSP70 to Japanese flounder HSC71}

was $56 \%$ by multiple alignment using malign. Little signal was observed on RNA isolated from unheat-shocked cells. On the other hand, a significant signal increase of approximate $2.2 \mathrm{~kb}$ and $2.4 \mathrm{~kb}$ bands were observed on RNA after heat shock for $20 \mathrm{~min}$. After heat shock for $40 \mathrm{~min}$, the signal of $2.2 \mathrm{~kb}$ band was decreased and the signal of $2.4 \mathrm{~kb}$ band was increased. The possible reason of the size heterogeneity of Japanese flounder HSP70 mRNAs is that the differences in length of $3^{\prime}$-untranslated regions. At present, it is unclear that the exact reason for differences in the expression patterns of 2.2 and $2.4 \mathrm{~kb}$ HSP 70 bands. As shown in Fig. 3, Japanese flounder HSC71 mRNA was constitutively expressed under normal ( 0 time) or heat- 
968

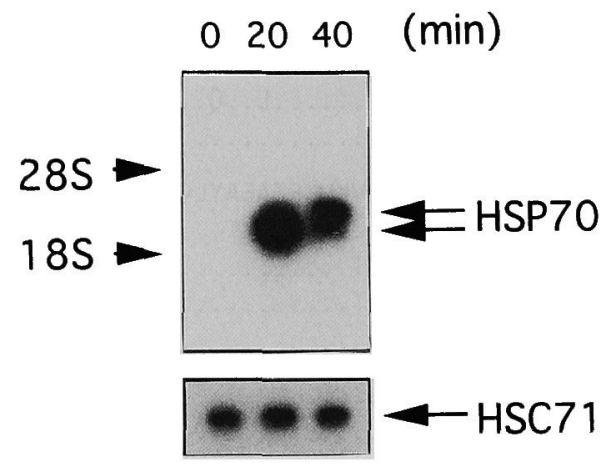

Fig. 3. RNA expression analysis. Northern blot analyses were carried out using $10 \mu \mathrm{g}$ total RNA isolated from control $(0 \mathrm{~min})$ and heatshocked $\left(37^{\circ} \mathrm{C}\right.$ for 20 or $\left.40 \mathrm{~min}\right)$ Japanese flounder cells in early passage. The probe for hybridization was prepared from the cloned HSP70 cDNA fragments (1898 to $2112 \mathrm{bp}$ ) containing $3^{\prime}$-untranslated regions (1921 to $2112 \mathrm{bp}$ ). As an internal control, the cDNA fragment of Japanese flounder HSC71 containing 3'-untranslated regions ${ }^{4}$ was used. Hybridization was done under the same condition described above.

shocked conditions (20 and $40 \mathrm{~min}$ ).

Although the patterns in expression of HSP70 and HSC71 are different (Fig. 3), it was shown that they have similar structure and function as molecular chaperons in cultured cells of mammals. ${ }^{12)}$ In yeast, genetic analysis has shown that HSP70 compensated for those growths at higher temperature on behalf of the cognate genes which expressed constitutively. ${ }^{13)}$ These findings and high similarity of HSP70 and HSC71 suggested that synthesized HSP70 and HSC71 under stress conditions may have similar functions in Japanese flounder.

The analyses on expression patterns and functions of Japanese flounder HSP70 and HSC71 in the embryos during development under normal and stress conditions are now in progress.

Acknowledgments We are grateful to Mr. S. Yamagata, Yamagataya Suisan, for providing the Japanese flounder eggs. This study was supported in part by a Grant-in-Aid for Scientific Research from the Ministry of Education, Science, Sports and Culture of Japan and by a grant from the Research for the Future Program of the Japan Society for the Promotion of Science (97L00902).

\section{References}

1) M. Yamashita: Genes associated with stress response, in "Fish DNA" (ed. by T. Aoki, F. Takashima, and T. Hirano), Koseisha Koseikaku, Tokyo, 1997, pp. 219-243 (in Japanese).

2) R. I. Morimoto, A. Tissieres, and C. Georgopoulos: Stress Proteins in Biology and Medicine, Cold Spring Harbor Laboratory Press, New York, 1990, pp. 1-450.

3) R. I. Morimoto, A. Tissieres, and C. Georgopoulos: The Biology of Heat Shock Proteins and Molecular Chaperons, Cold Spring Harbor Laboratory Press, New York, 1994, pp. 1-610.

4) Y. Yokoyama, H. Hashimoto, S. Kubota, M. Kinoshita, H. Toyohara, M. Sakaguchi, and M. Kanamori: Complementary DNA Cloning of HSC71, a $71 \mathrm{kDa}$ Heat Shock Cognate Protein, in Japanese Flounder Paralichtys olivaceus. Fisheries Sci, , 64, 388392 (1998).

5) C. Hunt and R. I. Morimoto: Conserved features of eukaryotic hsp70 genes revealed by comparison with the nucleotide sequence of human hsp70. Proc. Natl. Acad. Sci. USA, 82, 6455-6459 (1985).

6) J. A. Gutierrez and V. Guerriero Jr.: Chemical modifications of a recombinant bovine stress-inducible $70 \mathrm{kDa}$ heat-shock protein (Hsp70) mimics Hsp70 isoforms from tissues. Biochem. J., 305, 197-203 (1995).

7) F. M. Longo, S. Wang, P. Narasimhan, J. S. Zhang, J. Chen, S. M. Massa, and F. R. Sharp: cDNA cloning and expression of stressinducible rat hsp70 in normal and injured rat brain. $J$. Neurosci. Res., 36, 325-335 (1993)

8) T. Maniatis, E. F. Fritsch, and J. Sambrook: Molecular Cloning: A Laboratory Manual, 2nd edn. Cold Spring Harbor Laboratory Press, Cold Spring Harbor, NY, 1989.

9) C. D. Flaherty and D. Mckay: Nucleotide sequence of the cDNA of a bovine 70 kilodalton heat shock cognate protein. Nucleic. Acid Res., 18, 5569 (1990).

10) K. O'Malley, A. Mauron, J. D. Barchas, and L. Kedes: Constitutively expressed rat mRNA encoding a 70-kilodalton heat-shocklike protein. Mol. Cell. Biol., 5, 3476-3483 (1985).

11) B. Dworniczak and M. E. Mirault: Structure and expression of a human gene coding a $71 \mathrm{kd}$ heat shock 'cognate' protein. Nucleic. Acid Res., 15, 5181-5197 (1987).

12) C. R. Brown, R. L. Martin, W. J. Hansen, R. P. Beckmann, and W. J. Welch: The constitutive and stress inducible forms of hsp70 exhibit functional similarities and interact with one another in an ATP-dependent fashion. J. Cell Biol., 120, 1101-1112 (1993).

13) E. A. Craig and K. Jacobsen: Mutations in cognate genes of Saccharomyces cerevisiae hsp70 result in reduced growth rates at low temperatures. Mol. Cell. Biol., 5, 3517-3524 (1985). 